\title{
Classification of a Course Deduction Teachings Innovation
}

\author{
Haozhang Sun, Xiaomin Ji, Feng Wang \\ Xi'an University of Technology, Xi'an, China \\ Email: sunhaozhang@126.com,6397726@qq.com,18594687@qq.com
}

Received 2012

\begin{abstract}
In this paper, folk art class, for example,Clarify in teaching should be based on the course (folk art) in a form for the foundation, working people's living and production based on the main line of folk art forms of the associated property, are classified teaching point of view, examples focus on respect to comply with the regulatory class method, the habits of civil labor, the linkages between the various forms of folk art and the common features of the classification of ideas, as well as the form of derivatives, function approximation, the process of convergence classified. I hope a positive reference value for the improvement of education and teaching in the classification of cognitive and curriculum pedagogy.
\end{abstract}

Keywords: Classified Teaching; Classification Method; Deduction

\section{Introduction}

The folk art is among the laborers, but also of their own art. The working masses in productive labor, social activities, I, in order to meet the spiritual life of the needs of their own creation and spread of a simple, free form of ideographic and application of them. It is not the composition of the work, techniques, materials classification, but mankind has created a variety of art forms in the form of the private sector [1].

Common teaching methods prevalent in the only listed on a separate introduction and case of the several manifestations, many folk art forms and manifestations of mutual relations and internal relations are involved, for students, folk art seems to be only performance classdescribed in a single case, difficult to understand the nature of folk art widely distributed folk born in the life of the people's labor productivity, or simply impossible to understand. Merely express the people's yearning for a better life "and the simple concept of trend Kat evil spirits" and superficial level, or bamboo, straw, batik, clay sculpture, paper cutting, blue cloth, folk toys ... and so on through a simple list of law [2]. Students' understanding of the folk art is isolated and fragmented the concept of nouns and pictures, or even just the impression of a few isolated works of art. Therefore classified as teaching methods and the understanding of the nature of the origin of folk art is particularly important.

To make the students thorough understanding of the folk art and knowledge of folk art and folk art to generate interest and enthusiasm, should be associated with various forms of folk art in a specific teaching practice-based line, the development of folk art was born and the presence of the foundation for basis for the classification of folk art of teaching. Should be based on the masses of working people's living and production in the regulatory class method is based on respect of compliance with civil labor habits, and strive to achieve the objective rustic real. Between various forms of folk art in the form of derivative, function approximation, the process of convergence and the relationship between a more systematic classification of teaching.

Analyze and explain the concept of association, the integrity of folk art, to solve the isolation is prone to various forms of folk art courses, the intellectual content of dispersed messy, and students' understanding of the folk art category recognizes only stay in the individual works of art presents the outlook on the situation.

\section{Classify by Derivative Form}

The form of derivatives classified by the characteristics of folk art forms of the derivative relationship between the various forms of study from the meaning of function, classified according to its most fundamental and most primitive form of derived relations in the form. Series in the form of derivative chain of folk art form, first create a form of derivative perceptual concepts into the aesthetic characteristics of rational analysis.

For example, it is usually in the folk art teaching of the folk art form of a separate listed and introduced the concrete form by the teachers all the information at hand for the introduction of the basis of information and explanation on the detailed, lack of information of the corresponding explanation and analysis is relatively crude. Students to obtain and understand knowledge also the corresponding single-sided, isolation, lack of a rational understanding of deep-seated and Global Perception. In the students the impression that the relationship between the various types of folk art forms like straight poplar forest, and exist independently of each other, non-interference in each other's exchanges.

But in fact between the forms of folk art of paper cutting, dyeing, embroidery, sewing, plaiting are interdependent and interrelated. Reference to the original form of paper cutting is done by the beginning of the embroidery draft, known as the pattern of paper flowers around after the original fabric color printing, and embroidery, printing and dyeing and fabric in the embroidery, respectively, at the beginning of life with the use of functional the performance of the final form. From the process perspective, including a series of processes of textile, dyeing, sewing, embroidery, plaiting, etc.. History succinct, with the improvement in material standards of living conditions of working people, the spirit of the aesthetic needs of continuous improvement, these original in many aspects of the same 
production chain have to grow up, combined with the geographical and cultural differences were formed a variety of different styles and the face of folk art forms, known as paper cutting, dyeing, embroidery, cloth. However, the cause of the beginning of its birth, the formation of living, productive labor needs to each other derivatives is not not destroy, but also can not let go. In the social division of labor "men plow and women weave" these more than the woman at home to complete, so in general terms as "female red", but also for the "workers" or "female power". Include seeing today is the concept of female red paper cutting, dyeing, embroidery, sewing, plaiting form of folk art, multi-generations of mothers and daughters-law passed along, but also referred to as the "mother's art" [3].

Derivative in the form of folk art, folk art courses taught and teaching activities, relations are classified, the introduction of the concept of female red will be a variety of folk art form of association runs through to explain, obviously vivid. So Road, the story was thorough and meticulous, first emotionally closer to the distance between the students and folk art. Paper cutting, dyeing, embroidery, sewing, plaiting, these beautiful art forms and works no longer seem lofty and difficult, as last night, mother manual. Emotional closer to inevitably lead to the deepening of understanding, the memory of the firm. In other words, perceptual thorough rational understanding is profound, and will greatly improve the efficiency of students of folk art to understand and classroom.

\section{Classify by Technical Process}

The process of convergence classified by studying folk art form of the existing form, find the common application of media or expression vector, in specific teaching to explain the main line, the process of establishing its public expression vector successively in series to each step of the process, On this basis, to analyze the characteristics of the form. Abstract concepts to guide the students with the convergence characteristics of the process procedures, or rely on a public carrier, understanding, memory, push the performance associated with various forms of folk art. Think of all kinds all kinds of folk art in the form and works by the carrier craft procedure.

For example, in many forms of folk art, stone carvings multi-pillar, the amount of Square, stigma, column bases, doors and windows, stone, Shek Kwu and lions of stone elephants, Shuanma stone and other building components or accessories. The brick works for the main gate, door cover, flowers, windows, screen wall, gable wall eaves and roof and other parts of the building's exterior decoration. The carvings are mostly the doors and windows of the residential building itself, and household fan, shrines and internal furniture, wood carving decoration graphical form are functional as a precondition, with openwork carving, relief carvings and other forms. Lacquer works with woodcarving combination, taking into account the dual function of the corrosion protection and beautification of buildings and furniture, with richly ornamented effect "national characteristics.

Folk will be able to engage in some kind of specialized technical labor or external addition to the daily labor in a field of expertise called craftsmen. For example, to grasp the stone carving skills of the workers called a mason, will learn the the woodcut skills of workers known as the carpenter. Introduced in teaching the concept of "Carpenter", the process works and the works of folk art known as "Carpenter Gong" or "Carpenter workers. Private building construction and decoration as the main line craftsmen labor for clues decoration along the building construction process followed, the series engrave stone, carved bricks, carved wood, decorated with paint, and other folk art, craft and form. So has the support of the "architecture" and "Carpenter work" series, the students have a basis point and the basis for memory and understanding of the appropriate folk art, the ability to abstract concepts through construction and the work of Carpenter, "think of the concrete (building The decoration of the inside and outside the various types of decoration and decorative craft) building up concepts quickly into the image. Such as stone, brick, wood carvings, lacquer ware, and so on all kinds of folk art forms filed into the room like beads out of a variety of processes, each process in turn appear vivid, deep and easy to remember to understand.

\section{Classify by Function Approximation}

Functional approximation classified France summed up by analyzing the function of folk art forms, common to many folk art forms are an approximation property. On the specific operation, regardless of the history function, social function, or the existing functions to find out by comparing the induction between the various folk art forms of common or similar special function levy, the functional characteristics based on the division, summed up with the same or similar functional characteristics of folk art form.

For example, sugar, clay sculpture, shadow play, kite, the illuminations of these folk art forms of distribution at different times in different regions of the Spring and Autumn seasons, urban and rural marketplace, isolated from each other independent of each other. Teaching and other forms of folk art mixed with each other list them all, like a broken thread people upset unbearable, the trade-off, not to mention the understanding of memory, imitation draws.

Can be summarized by analyzing the induction of its features are: sugar are the streets and lanes of folk art, multi-blow or two forms of painting, by the the hawkers Diaodan street, flowers, birds, fish and insects with sugar as raw material, the text that play video and other image to please the children. Clay is the fields of folk art, clay-based material to shaping the Zodiac hanging tiger mud toys, to impose a green and red painted for the children and grandchildren to play with another auspicious. The shadow play is a backstage folk art, from pork, beef, animal skin, cut engraved chisel painting process, shaping the character of theater history, with light wax film with the hit song singing of folk artists, operas rhetoric interpretation of the classic story, entertaining enlightenment function, is one of the important spiritual and cultural life in the peoples of the old labor. Kite wood Harrier kite folk art from the Moti "Wood Harrier incoming civil evolved into bamboo paper structure, to learn the New Year decorative features, more in the spring flying entertainment for all ages. Lantern jubilant festivals of folk art, common in old season or marriage Shou festive materials for bamboo and rattan paper silk, its shape is changing in style, in civil society at the same time the role of entertainment and cultural symbols.

Classified divided based on function approximation can be found in the sugar people, clay sculpture, shadow puppets, kites, illuminations and other forms of folk art have the nature of the educational, entertainment, belong to the same culture and entertainment areas. Then be summarized by reference to the 
concept of the common folk vocabulary of "playing the goods", can be covered by the sugar people, clay sculpture, shadow puppets, kites, illuminations, etc., these approximate the functional properties of folk art forms. Classification with function approximation and the unifying of the concept of "playing goods, originally scattered sugar, clay sculpture, shadow puppets, kites, illuminations of these folk art forms of have a connection point and similarity, no longer seem complicated mess bear, hard to remember, teaching and thus add to the fun.

Courses taught and teaching activities in folk art, folk art, the function approximation characteristics are classified into "playing the stock" concept, a variety of folk art forms together classified to explain everything for the condensate. Such a focus on integration of the classification of explanations, from the functional characteristics for students to find specific forms of mutual contact of the folk art and easy to remember the connection point. Taught to help students understand the understanding of folk art at the same time, the integrated approach to learning folk art induction.

\section{REFERENCES}

Lu Shengzhong, The basic concepts of "folk art", in Art Research, vol.1, pp.56,1994.

Deng Xingfu, "Definition and classification of 'folk art"' ,in Art Observation, vol.2, pp.35,1997.

Editorial offices of the Voice of Han:Chinese female red-mother's arts,Beijing:Peking University Press,2006 